\title{
AN INQUIRE ON THE PRIOR KNOWLEDGE OF MEDICAL STUDENTS ABOUT RHEUMATOLOGY DURING
} THEIR ACADEMIC GRADUATION

Manoella Gotardo Aguiar Gurgel (Unifor, Fortaleza, CE, Brasil), Amanda Coelho Sales Bernardes (Unifor, Fortaleza, CE, Brasil), Beatriz Lis Soares Holanda (Unifor, Fortaleza, CE, Brasil), Giselle Aguiar Pinto

(Unifor, Fortaleza, CE, Brasil), Thalia Sousa Bezerra (Unifor, Fortaleza, CE, Brasil), Max Victor Carioca Freitas (Unifor, Fortaleza, CE, Brasil), Priscila Dourado Evangelista (Unifor, Fortaleza, CE, Brasil)

\section{BACKGROUND}

It is important for a doctor to learn how to approach musculoskeletal diseases, since aging and sedentary lifestyle are important factors that influence the onset of affections in this system. Furthermore, the proper understanding of autoimmune and inflammatory processes helps to recognize the correct etiology of those diseases, which are the main cause for seeking medical assistance in primary care clinics. The purpose of this study is to make a statistical analysis out of the prior knowledge of medical students about rheumatology and their exposure to the subject during the graduation, contemplating the importance of the area in medicine.

\section{MATERIALS AND METHODS}

This is a descriptive cross-sectional study, based on the results of anonymous online survey, applied through Google Forms, receiving 102 answers from medical students out of both private and public institutions in the state of Ceará, collected in June of 2019.

\section{RESULTS}

Out of the 102 answers analyzed, $61.8 \%$ were female and $38.2 \%$ male, being the majority (89.2\%) of the students from private institutions. Regarding the period students were in, $25.5 \%$ of them were in the third year, $23.5 \%$ in the fourth, $22,4 \%$ in the second, $14.7 \%$ in the first, $12.7 \%$ in the fifth and only $1 \%$ was in the sixth year. Among the answers, $98 \%$ of the students were in favor of a greater academic exposure to rheumatology, however $52.9 \%$ had no previous contact to the subject. Of those who had previous contact, $73.5 \%$ had both theoretical and practical contact, $14.3 \%$ had only practical contact and $12.2 \%$ had only theoretical contact. When asked if they felt confident about situations involving rheumatologic issues through out the academic trajectory, $44.1 \%$ were unable to give an opinion, $28.4 \%$ answered that they weren't certain and $27.4 \%$ answered that they were confident about their knowledge. Regarding the relevance, $68.6 \%$ considered the study of rheumatology during their graduation to be relevant or very relevant, and no student considered it to be irrelevant.

\section{CONCLUSION}

We concluded that there is a high prevalence among the students of those who had no prior contact with Rheumatology so far in their graduation, even though most of them find it relevant. Furthermore, the minority feels confident to deal with rheumatological complaints in their professional future. Due to the present study findings, we believe it is necessary to stimulate the approach to rheumatology during the medical graduation, since it is a demand from the students to improve their knowledge about the area. 